Louisiana State University

LSU Digital Commons

Faculty Publications

Department of Geology and Geophysics

$1-5-2017$

\title{
Nickel speciation in cement-stabilized/solidified metal treatment filtercakes
}

Amitava Roy

Louisiana State University

Julia A. Stegemann

University College London

Follow this and additional works at: https://digitalcommons.Isu.edu/geo_pubs

\section{Recommended Citation}

Roy, A., \& Stegemann, J. (2017). Nickel speciation in cement-stabilized/solidified metal treatment filtercakes. Journal of Hazardous Materials, 321 (None), 353-361. https://doi.org/10.1016/

j.jhazmat.2016.09.027

This Article is brought to you for free and open access by the Department of Geology and Geophysics at LSU Digital Commons. It has been accepted for inclusion in Faculty Publications by an authorized administrator of LSU Digital Commons. For more information, please contact ir@lsu.edu. 


\title{
Nickel Speciation in Cement-Stabilized/Solidified Metal Treatment Filtercakes
}

\author{
Amitava Roy and Julia A. Stegemann ${ }^{\mathrm{b}}$
}

${ }^{a}$ J. Bennett Johnston, Sr., Center for Advanced Microstructures and Devices, Louisiana State University, Baton Rouge, LA 70806, USA; E-mail: reroy@1su.edu

${ }^{\mathrm{b}}$ Corresponding Author; Centre for Resource Efficiency \& the Environment, Department of Civil, Environmental \& Geomatic Engineering, University College London, Chadwick Building, Gower Street, London WC1E 6BT, UK; E-mail: j.stegemann@ucl.ac.uk; Phone: +44(0)207 6797370

ABSTRACT: Cement-based stabilization/solidification (S/S) is used to decrease environmental leaching of contaminants from industrial wastes. In this study, two industrial metal treatment filtercakes were characterized by X-ray diffractometry (XRD), thermogravimetric and differential thermogravimetric analysis (TG/DTG) and Fourier transform infrared (FTIR); speciation of nickel was examined by X-ray absorption (XAS) spectroscopy. Although the degree of carbonation and crystallinity of the two untreated filtercakes differed, $\alpha$-nickel hydroxide was identified as the primary nickel-containing phase by XRD and nickel $\mathrm{K}$ edge XAS. XAS showed that the speciation of nickel in the filtercake was unaltered by treatment with any of five different $\mathrm{S} / \mathrm{S}$ binder systems. Nickel leaching from the untreated filtercakes and all their stabilized/solidified products, as a function of $\mathrm{pH}$ in the acid neutralization capacity test, was essentially complete below $\mathrm{pH} \sim 5$, but was 3-4 orders of magnitude lower at $\mathrm{pH} 8-12$. S/S does not respeciate nickel from metal treatment filtercakes and any reduction of nickel leaching by $\mathrm{S} / \mathrm{S}$ is attributable to $\mathrm{pH}$ control and physical mechanisms only. $\mathrm{pH}$-dependent leaching of $\mathrm{Cr}$, $\mathrm{Cu}$ and $\mathrm{Ni}$ is similar for the wastes and s/s products, except that availability of $\mathrm{Cr}, \mathrm{Cu}$ and $\mathrm{Zn}$ at decreased $\mathrm{pH}$ is reduced in matrices containing ground granulated blast furnace slag. 
KEYWORDS Stabilization/solidification; X-ray absorption spectroscopy; electroplating sludge; waste treatment; wasteform; leaching

\section{INTRODUCTION}

Treatment by stabilization/solidification with cement-based binders $(\mathrm{S} / \mathrm{S})$ is an option for wastes that cannot be prevented or reduced, such as metal-bearing industrial wastes and wastewaters. S/S aims to provide a chemical environment where contaminants have lower solubility, and a physical matrix of low hydraulic conductivity, to minimize leaching when the resulting cement-based product is utilized or land-disposed.

Metal-bearing wastewaters are usually acidic, and are typically treated by neutralization with excess calcium hydroxide to produce a hydroxide sludge that is dewatered by filter pressing. The filtercake tends to undergo carbonation from the atmosphere, before possible further treatment by $\mathrm{S} / \mathrm{S}$. The mineralogical composition of such metal treatment filtercakes, and the speciation of contaminants in them, is controlled by both kinetic and thermodynamic factors and has not been well-characterized. In fact, the initial precipitate is often colloidal and the solid phases are unstable or metastable and therefore different from predictions based on thermodynamic equilibrium.

Characterization of waste mineralogy and speciation of contaminants in wastes and their stabilized/solidified $(\mathrm{s} / \mathrm{s})$ products is critical for understanding contaminant leachability in laboratory tests and the environment, as well as development of effective treatments. The effect of $\mathrm{S} / \mathrm{S}$ on metal contaminant speciation and leachability is of particular interest, as respeciation of contaminants is arguably a primary goal of the treatment. In theory, $\mathrm{S} / \mathrm{S}$ results in precipitation or co-precipitation of metal ions, e.g., as hydroxides, or up-take by cement hydration products, e.g., in calcium silicate hydrate, or ettringite and/or monosulphate-type phases, possibly including a change in oxidation state [1]. Papers about $\mathrm{S} / \mathrm{S}$ commonly speculate about contaminant speciation without evidence, e.g., reporting leaching results for regulatory tests such as the USEPA Toxicity Characteristic Leaching Procedure (e.g., [2, 3]), and/or as "\% immobilization" (the difference between the total concentration and the leached amount as a percentage of the total concentration (e.g., [3-5]). Such results are arbitrary in relation to potential environmental leaching, since they can be manipulated by changing the leaching conditions ( $\mathrm{pH}$, liquid-to-solid ratio, contact method), and are unhelpful in elucidating the 
contaminant immobilization mechanism. Questionable evidence of respeciation is often based on application of a sequential extraction procedure (e.g., [6], such as that originally proposed by Tessier et al. [7], though this has been shown to be highly inaccurate for s/s products [8].

A variety of instrumental techniques are available to examine mineralogy and contaminant speciation of wastes and cement-based materials. X-ray diffractometry (XRD) is widely used for mineralogical characterization of crystalline samples, but is of limited help for non-crystalline materials. Fourier transform infrared (FTIR) microscopy and thermal analysis are also routinely used to investigate cementitious materials. None of these techniques is element specific and they are not useful for study of elements at low concentrations. In contrast, X-ray absorption spectroscopy (XAS) can track a particular element at relatively low concentrations in a complex host matrix and probe its local structure and speciation, without a requirement for crystallinity.

The application of XAS to complex matrices in relation to environmental fate and behavior of contaminants is still relatively rare, but it has been employed in a limited number of studies of the speciation of metals in cement pastes, including chromium [9], cobalt [10], copper [11], lead [12], neodymium [13], selenium [14], tin [15], uranium [16] and zinc [17], as well as nickel [18-20]. Apart from Rinehart et al. [9], who examined the oxidation state of chromium in a s $/ \mathrm{s}$ contaminated soil and showed that this was not affected by $\mathrm{S} / \mathrm{S}$, and Hsaio et al. [11], who indicated that $\mathrm{S} / \mathrm{S}$ respeciated $\mathrm{CuCl}_{2}$ and reduced forms of copper in municipal waste incinerator air pollution control residues to $\mathrm{Cu}(\mathrm{OH})_{2}$, other studies have all prepared hydrated cement pastes by mixing pure solutions of soluble metal salts with cement powder. This contact mechanism is unrealistic, as contaminants in wastes are rarely fully dissolved, and the speciation observed in this way may not apply in cement-based systems containing real wastes. Previous scanning electron microscopy work has shown encapsulation of sludge particles, tens of $\mu \mathrm{m}$ in size, in the cement matrix [21]. Microscopy, however, cannot infer whether respeciation occurred.

This study therefore used multiple techniques, including XAS, to investigate the mineralogy and speciation of nickel in two real metal treatment filtercakes, as well as in five different $\mathrm{s} / \mathrm{s}$ products prepared from one of the filtercakes using different $\mathrm{S} / \mathrm{S}$ formulations. $\mathrm{pH}$ dependent leaching of $\mathrm{Ni}, \mathrm{Cr}, \mathrm{Cu}$ and $\mathrm{Zn}$ in both filtercakes and their s/s products was also examined. 
Nickel was studied as an element of environmental concern that is more common in metal treatment filtercakes than other industrial wastes usually treated by S/S. Previous work with these materials found the trivalent oxidation state of chromium to be unaltered by $\mathrm{S} / \mathrm{S}$, but indicated that hydroxo complexes with similar coordination but slightly different bond distances were formed in s/s products[22]. Speciation of copper and zinc, also present in these wastes, has not yet been investigated. This work was conducted in the context of a larger project led by University College London (UCL) to increase transparency of S/S technology by developing process envelopes for generic $\mathrm{S} / \mathrm{S}$ of the most common/problematic residual waste types, i.e., to investigate relationships between engineering and leaching properties and s/s product composition $[23,24]$.

\section{Experimental materials and methods}

\subsection{Filtercakes}

Two metal treatment filtercakes were obtained by UCL from anonymous industrial sources, designated "ST" and "TX" in the following text. The filtercakes were produced by filterpressing sludges from neutralization of plating wastes with calcium hydroxide, in a process that is open to the atmosphere. The residual moisture contents of ST and TX were $57 \%$ and $78 \%$ wet mass, respectively. To obtain representative results in the $\mathrm{S} / \mathrm{S}$ trials, the filtercakes were dried to constant mass at $60^{\circ} \mathrm{C}$, crushed to a particle size of $<1 \mathrm{~mm}$, homogenized and reconstituted to a moisture content of $50 \%$ wet mass before being treated by $\mathrm{S} / \mathrm{S}$. The chemical compositions of the dried filtercakes were determined by inductively coupled plasma optical emission or mass spectroscopy (ICP-OES/MS) following aqua regia digestion, with measurement of anions by ion chromatography of the extract from a 10:1 water extraction. Loss-on-ignition (LOI) of the filtercakes was determined at $550^{\circ} \mathrm{C}$, and total organic carbon (TOC) content was measured in a LECO furnace. The typical composition ranges of the filtercakes for several samples taken over more than a year are shown in Table 1, including the specific samples used in this work (i.e., totals shown in Figure 5 and used in Table 3). The variations in element concentrations observed are typical of industrial wastes, whereby concentrations of the soluble ions potassium, sodium and nitrate were particularly variable, but quite low. The TOC content of both sludges was low $(<3.3 \%)$, so the much higher LOI values $(<61 \%)$ suggest the presence of inorganic compounds that decompose at a relatively low 
temperature (see also 3.1.3). Nickel was present at $\%$ levels in both sludges, with a four-fold concentration variation in sludge ST and a two-fold variation in sludge TX.

\subsection{Preparation of stabilized/solidified products}

The binders used in S/S were Portland cement on its own, or Portland cement or hydrated lime $\left(\mathrm{Ca}(\mathrm{OH})_{2}\right)$ blended with power plant fly ash (from combustion of pulverized bituminous coal, i.e., "Class F" or "pfa") or ground granulated blast furnace slag. The five formulations studied in this work are summarized in Table 2. The overall concentrations of selected elements in each formulation (Table 3) were calculated based on the elemental compositions and proportions of filtercake and binder, and the moisture contents of the $\mathrm{s} / \mathrm{s}$ products determined by drying at $60^{\circ} \mathrm{C}$ after 28 -day curing. The dried $\mathrm{s} / \mathrm{s}$ products were also ground and used for the following XAS, mineralogical characterization, and leaching studies.

\subsection{Standards}

The reference materials examined for comparison with the FTIR spectra, TG curves and XAS spectra are summarized in Table 4; comparisons with data from the literature are cited in the text, where appropriate.

\subsection{X-Ray Absorption Spectroscopy}

XAS, including extended X-ray absorption fine structure (EXAFS) and X-ray absorption near edge structure (XANES), was performed at the electron storage ring of J. Bennett Johnston, Sr., Center for Advanced Microstructures and Devices (CAMD), Louisiana State University, Baton Rouge. The ring is operated at $1.3 \mathrm{GeV}$. A wavelength shifter in a straight section of the ring operating at 7.5 Tesla increases the workable X-ray energy range to about $30 \mathrm{keV}$. Data were collected at the Wavelength Shifter Double Crystal Monochromator (WDCM) beamline of CAMD. The monochromator is a Lemonnier-type with design modifications made at Bonn University, Germany. The crystals in the monochromators can be easily exchanged to obtain any energy from $1.7 \mathrm{keV}$ to $30 \mathrm{keV}$. Germanium 220 crystals were used in the monochromator for the nickel K edge measurements. Nickel metal foil was used for monochromator calibration $(8333.0 \mathrm{eV})$. The measurements in fluorescence mode were conducted with a 13-element germanium solid state detector (Canberra Industries, Meridian, Connecticut, USA). The steps in 
each scan were $5 \mathrm{eV}$ up to $30 \mathrm{eV}$ below the edge, $0.3 \mathrm{eV}$ from $-30 \mathrm{eV}$ to $60 \mathrm{eV}$ above the edge, and $0.05 \mathrm{k}$ up to $1000 \mathrm{eV}$ above the edge, with 5 seconds integration at each step.

Multiple scans (2-5 each) were run at room temperature and were averaged using the ATHENA software[25]. Athena in Demeter was also used for principal component analysis. EXAFS fitting was performed with WinXAS [26]. Generally, the region between $3 \mathrm{k} / \AA$ and 14 $\mathrm{k} / \AA$ was fitted in r-space. The $\mathrm{S}_{0}{ }^{2}$ factor was obtained by fitting bunsenite (Table 6 ) and then kept constant for subsequent fitting of the s/s product spectra. Fitting was performed for only the first two shells, approximately the region of $1.0 \AA$ to $3.20 \AA$. FEFF paths were obtained from the crystal structure of $\beta$-nickel hydroxide [27]. A sample of $\beta$-nickel hydroxide (Table 6) was also fitted for comparison. To obtain a robust fit, the number of variables was kept as low as possible at the cost of a slightly higher chi square value.

\subsection{X-Ray Diffractometry}

The XRD patterns were also obtained at the CAMD WDCM beamline. A Huber fourcircle goniometer with flat plate geometry in theta-two theta configuration was used. The wavelength was set to nickel's $\mathrm{K}$ absorption edge (1.4878 $\AA$ ). The samples were scanned from 10 to $70^{\circ} 2 \theta$. The patterns were analyzed with MDI JADE 9.3.4 coupled with ICDD's PDF2 database.

\subsection{Fourier Transform Infrared Spectroscopy}

The FTIR spectra were obtained with a Thermo-Fischer Scientific Nicolet 670 spectrometer with an attenuated total reflectance (ATR, Smart iTR) attachment. Diamond plates were used in the ATR. The spectra were collected for the range 4000 to $650 \mathrm{~cm}^{-1}$.

\subsection{Thermal Analysis}

Simultaneous thermal analysis measurements were performed with a TA Instrument's Q600 SDT. The following parameters were used for the runs: purge gas of nitrogen with a flow rate of $100 \mathrm{~mL} / \mathrm{min}$; alumina pans; equilibration at $40^{\circ} \mathrm{C}$ for 10 minutes; heating rate of $5^{\circ} \mathrm{C} / \mathrm{min}$ from $40^{\circ} \mathrm{C}$ to $200^{\circ} \mathrm{C}$, followed by a heating rate of $10^{\circ} \mathrm{C} / \mathrm{min}$ up to $1000^{\circ} \mathrm{C}$. The amount of sample used was typically 10 to $20 \mathrm{mg}$. 


\section{8 pH-Dependent Leaching}

The cements used in $\mathrm{S} / \mathrm{S}$ provide a highly alkaline environment (usually $\mathrm{pH}>12$ ), which is a primary factor in contaminant immobilization. Since the natural environment is usually at a much lower $\mathrm{pH}(5-8)$, cement alkalinity will be neutralized over time at a rate dependent on the specific waste management conditions. Measurement of dissolved contaminant concentrations as a function of $\mathrm{pH}$ is therefore helpful in understanding long-term contaminant leachability and was measured using the Acid Neutralization Capacity [28] test with a liquid-to-solid ratio of 6:1 (now also adapted as DD CEN/TS 15364:2006). This test involves rotary extraction of a series of 11 subsamples of finely ground s/s product, each with a different amount of nitric acid, for 48h. Following measurement of $\mathrm{pH}$, each subsample is filtered and the filtrate is analyzed for the elements of interest by ICP-OES/MS. Results are plotted as element concentrations leached from the solid, on a logarithmic scale, as a function of $\mathrm{pH}$.

\section{Results and discussion}

\subsection{Filtercakes}

\subsubsection{X-Ray Diffractometry}

The XRD pattern of filtercake ST is shown in Figure 1a. The peaks are very broad, indicating very small crystallite size. The $0.253 \mathrm{~nm}$ and the $0.152 \mathrm{~nm}$ peaks are similar to those of $\alpha$-nickel hydroxide reported by Genin et al.[29]. Based on the $0.253 \mathrm{~nm}$ peak, the Scherrer equation suggests that the crystallite size for this phase is only $20 \AA$.

The XRD pattern of filtercake TX (inset in Figure 1a) is dominated by the peaks of highly crystalline calcite, with one unidentifiable additional peak with a d-spacing of $0.430 \mathrm{~nm}$.

\subsubsection{Fourier Transform Infrared Spectroscopy}

The FTIR patterns of both filtercakes are shown in Figure 1b, along with that of calcite. The aragonite and nickel carbonate reference materials were also run but are not shown here as there were few similarities. The hydroxyl (moisture) peak around $3300 \mathrm{~cm}^{-1}$ is broad in both filtercakes. No sharp hydroxyl peak suggestive of crystalline calcium hydroxide is present in either. The peak around $1600 \mathrm{~cm}^{-1}$ suggests the presence of molecular water. An unidentified peak at about $1010 \mathrm{~cm}^{-1}$ is common to both filtercakes. Calcite can be distinguished from vaterite by the typical peaks around $1400 \mathrm{~cm}^{-1}$ and $800-700 \mathrm{~cm}^{-1}$. Both are significant in the FTIR pattern for filtercake TX, indicating significant carbonation, whereas they are almost 
absent for filtercake ST, indicating a remarkable difference in the degree of carbonation of the two filtercakes, as is consistent with the XRD observations.
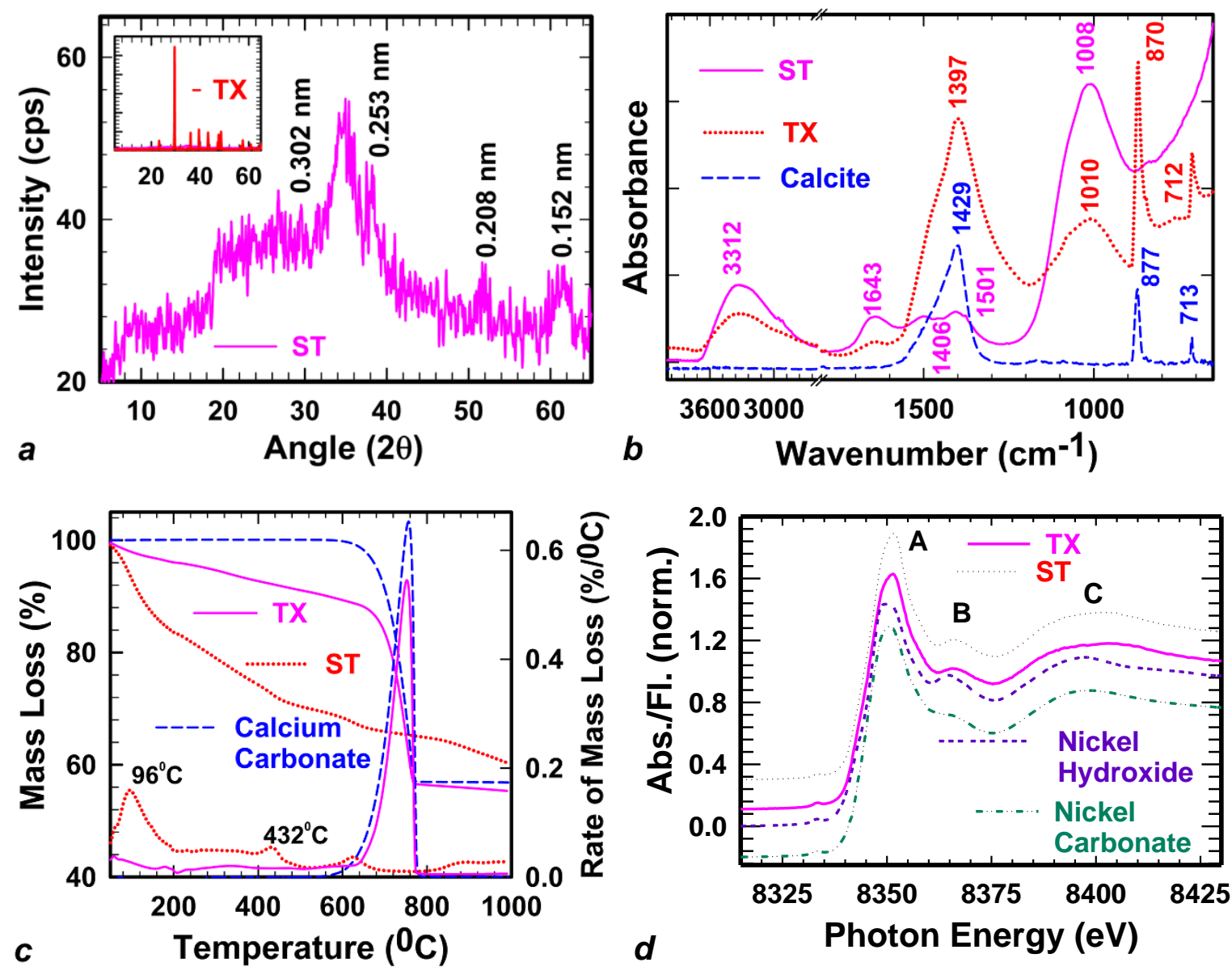

Figure 1. a) X-ray diffraction patterns for filtercakes ST and TX(inset); (b) Fourier transform infrared spectroscopy patterns for filtercakes ST and TX, compared with calcite; (c) Thermogravimetric patterns for filtercakes ST and TX, compared with calcite; and (d) X-ray absorption near edge spectroscopy patterns for Ni in filtercakes ST and TX, compared with $\beta$-nickel hydroxide and nickel carbonate. 


\subsubsection{Thermogravimetric Analysis}

Figure 1c shows a clear DTG peak at $730^{\circ} \mathrm{C}$ only for filtercake TX, indicating decomposition of about $73 \%$ calcite (Table 5). Three smaller DTG peaks can be observed for filtercake ST. The peak at $640^{\circ} \mathrm{C}$ suggests about $8.8 \%$ calcium carbonate [31], that at $432^{\circ} \mathrm{C}$ is likely about $19 \%$ uncarbonated calcium hydroxide, and that at around $96^{\circ} \mathrm{C}$ may be attributable to moisture, molecular water, or hydroxyl groups. In general, mass loss of both filtercakes is gradual, suggesting multiple overlapping thermal decomposition processes, and/or incongruent decomposition of amorphous, impure and/or metastable phases, which could include nickel hydroxide [32].

The higher level of carbonation for filtercake TX compared with ST observed by XRD, FTIR and TG is consistent with a higher $\mathrm{pH}$ measured for filtercake ST (Table 1), whereas the $\mathrm{pH}$ measured for $\mathrm{TX}$ is consistent with the equilibrium $\mathrm{pH}$ of a system dominated by calcite.

\subsubsection{X-Ray Absorption Spectroscopy}

The XANES spectra of the two filtercakes, along those of $\beta$-nickel hydroxide and nickel carbonate (Table 1) are shown in Figure 1d. The spectra for the two filtercakes are identical, except in white line intensity (A). The coincidence of the white lines shows that the oxidation state of nickel in the filtercakes is +II, as it is in the reference materials. Peak B, seen in the filtercakes and the $\beta$-nickel hydroxide, is absent in the nickel carbonate phase, suggesting that $\mathrm{Ni}$ is present as a hydroxide. However, it is slightly suppressed; this and a small shift in peak $\mathrm{C}$ in the filtercakes from its location in the $\beta$-nickel hydroxide spectrum indicates a slight difference in its form.

The Fourier transforms of the $\mathrm{k}^{2}$-weighted nickel $\mathrm{K}$ edge EXAFS spectra in $\mathrm{r}$ space for filtercake TX are shown in Figure 4a (for comparison with those of the s/s products in 3.2), with summary of the corresponding measurements and statistics in Table 6 . Bunsenite and $\beta$-nickel hydroxide are also included for comparison. The reference materials both show a strong first peak (Ni-O) at about $2.05 \AA$, but the position of the second peak (Ni-Ni) is $2.93 \AA$ for bunsenite and $3.12 \AA$ for $\beta$-nickel hydroxide; these $\mathrm{Ni}-\mathrm{O}$ and $\mathrm{Ni}-\mathrm{Ni}$ coordination numbers and distances, are similar to those reported in the literature [33]. The filtercake pseudo-radial distributions also show a strong first peak (Ni-O) at about $2.05 \AA$, but the second peak (Ni-Ni) is at about 3.05 to $3.06 \AA$. The heights of these second peaks for the filtercakes are also quite reduced in comparison with the bunsenite and $\beta$-nickel hydroxide, as they have lower Ni-Ni coordination 
numbers (ranging from 2.57 to 4.64). In an extensive study of nickel hydroxide battery material, Pandya et al. [33] reported a similar Ni-Ni distance and relatively low, variable second shell coordination for $\alpha$-nickel hydroxide.

XRD of filtercake TX suggests the presence of the $\alpha$-nickel hydroxide phase. Although the pattern is weak due to the very small size of the crystallites and relatively low overall concentration of $\mathrm{Ni}$, comparison of the XAS results with those for $\alpha$-nickel hydroxide in the literature [33] confirms the presence of $\alpha$-nickel hydroxide in the filtercakes. The Ni-Ni second shell is only partly filled, and the second peaks of the EXAFS spectral transforms therefore vary from sample to sample. Kurama [34] has also reported $\alpha$-nickel hydroxide in plating sludge, although his XRD pattern shows surprisingly high intensities for this relatively disordered phase, unlike our data. The $\alpha$-nickel hydroxide in the filtercake may have a turbostratic nature that explains the low XRD intensities.

\subsection{Stabilized/Solidified Products}

\subsubsection{X-Ray Diffractometry}

The XRD patterns of the s/s products (Figure 2a) show the crystalline phases expected in carbonated cement-based materials and those from power plant fly ash when it is a component. For example, Sample 1466 contains fly ash as a binder component (see Table 2 for formulation details $)$ and thus mullite $\left(3 \mathrm{Al}_{2} \mathrm{O}_{3} \cdot 2 \mathrm{SiO}_{2} / 2 \mathrm{Al}_{2} \mathrm{O}_{3} \cdot \mathrm{SiO}_{2}\right)$ and quartz $\left(\mathrm{SiO}_{2}\right)$ from the fly ash are

present in the diffraction pattern. The XRD patterns have low intensities generally, indicating the presence of few strongly crystalline phases. Calcite is common from carbonation. The $\alpha$-nickel hydroxide phase observed in filtercake TX could not be detected in the s/s products by XRD.

\subsubsection{Fourier Transform Infrared Spectroscopy}

The FTIR spectra of the s/s products shown in Figure $2 \mathrm{~b}$ have broad silicate peaks [35], with the peak maxima varying from $991 \mathrm{~cm}^{-1}$ to $950 \mathrm{~cm}^{-1}$. The proportions of different binders and polymerization after cement hydration and/or pozzolanic reaction ultimately determine the location of the silicate peak. The location of the silicate peaks in the FTIR patterns of the binder materials themselves (not shown) varies from as high as $1002 \mathrm{~cm}^{-1}$ in the power plant fly ash, to $900 \mathrm{~cm}^{-1}$ in the ground granulated blast furnace slag.

For all the formulations, carbonate peaks in the 1500 to $1400 \mathrm{~cm}^{-1}$ region (asymmetric, $v_{3}$ vibration) of the FTIR spectra clearly show two overlapping peaks, one centered around 1460 
$\mathrm{cm}^{-1}$, which is likely to be aragonite, and another centered around $1410 \mathrm{~cm}^{-1}$, which is likely to be calcite. The $v_{3}$ peak in powdered calcite can also be broad due to its anisotropic crystal structure [35]. There are also two sharp peaks around $860 \mathrm{~cm}^{-1}$, one at $876 \mathrm{~cm}^{-1}$ which is likely to be calcite, and another less intense peak at $856 \mathrm{~cm}^{-1}$ (out-of-plane bend, $v_{2}$ ), which is likely to be aragonite. The broad hydroxyl peaks in the FTIR spectra, around $3360 \mathrm{~cm}^{-1}$, may represent adsorbed moisture in the sample or the hydrated phases. No sharp peaks corresponding to calcium hydroxide are observed. The peak from free water around $1600 \mathrm{~cm}^{-1}$ is also quite broad.

\subsubsection{Thermogravimetry}

The DTG curves of the s/s products shown in Figure 2c have similar shapes, suggesting that similar phases are present, but the peak heights vary. In the low temperature range, the peaks around $60^{\circ} \mathrm{C}$ correspond to ettringite $\left(\mathrm{Ca}_{6} \mathrm{Al}_{2}\left(\mathrm{SO}_{4}\right)_{3}(\mathrm{OH})_{12} \cdot 26 \mathrm{H}_{2} \mathrm{O}\right)$, and the peaks around $80^{\circ} \mathrm{C}$ correspond to gypsum $\left(\mathrm{CaSO}_{4} \cdot 2 \mathrm{H}_{2} \mathrm{O}\right)$. Around $440^{\circ} \mathrm{C}$, peaks from the breakdown of calcium hydroxide are seen. Quantification of the mass losses from the TG curves shows that the amount of calcium hydroxide varies, from a high of $13.9 \%$ in Sample 1475, to undetectable in Sample 1478. In the region where the calcium carbonate phases break down, from about $500^{\circ} \mathrm{C}$ to
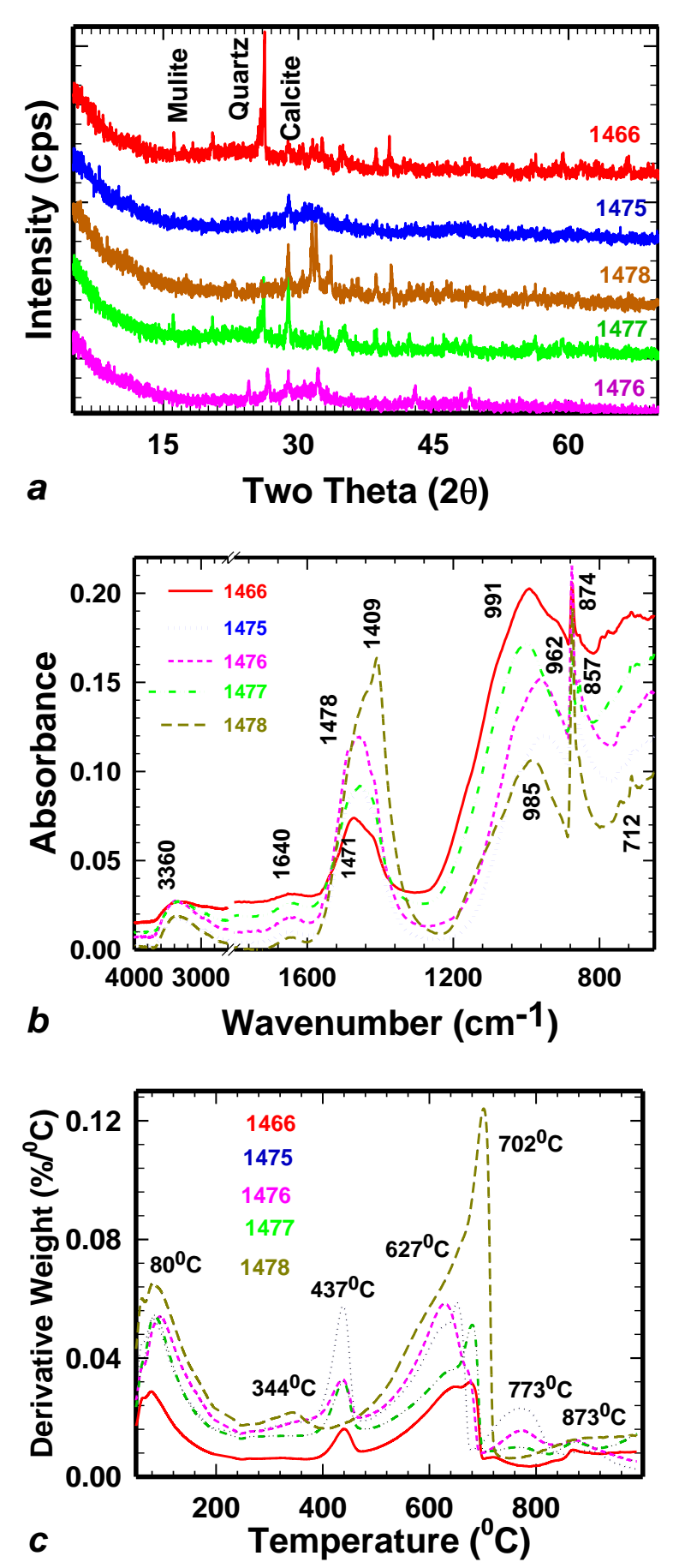

Figure 2. X-ray diffraction patterns (a),

FTIR patterns (b), and differential

thermogravimetric curves (c) of stabilized/solidified products prepared with filtercake TX (see Table 2 for formulations). 
$700^{\circ} \mathrm{C}$, peaks are seen for all the s/s products. The calcium carbonate peak shapes are complex, unlike that of pure calcite or the filtercake (Figure 1c). The amount, grain size and the nature of the carbonate phases can all contribute to the complex shape. It seems likely that the calcium carbonate is coming from two sources, the filtercake and the binder. The variation in calcium hydroxide and carbonate contents between the samples, which correlate inversely (Table 5), may be due to retardation of the hydration reaction of the cement by the waste, a difference in the pozzolanic reaction rates of the slag or fly ash or could be random.

\subsubsection{X-Ray Absorption Spectroscopy}

Figure 3a shows the nickel K edge XANES spectra of the s/s products along with that of the filtercake TX. The edge location (derivative of the white line, not shown) is identical for all of them, indicating the same oxidation state for nickel in the filtercake and the s/s products. The
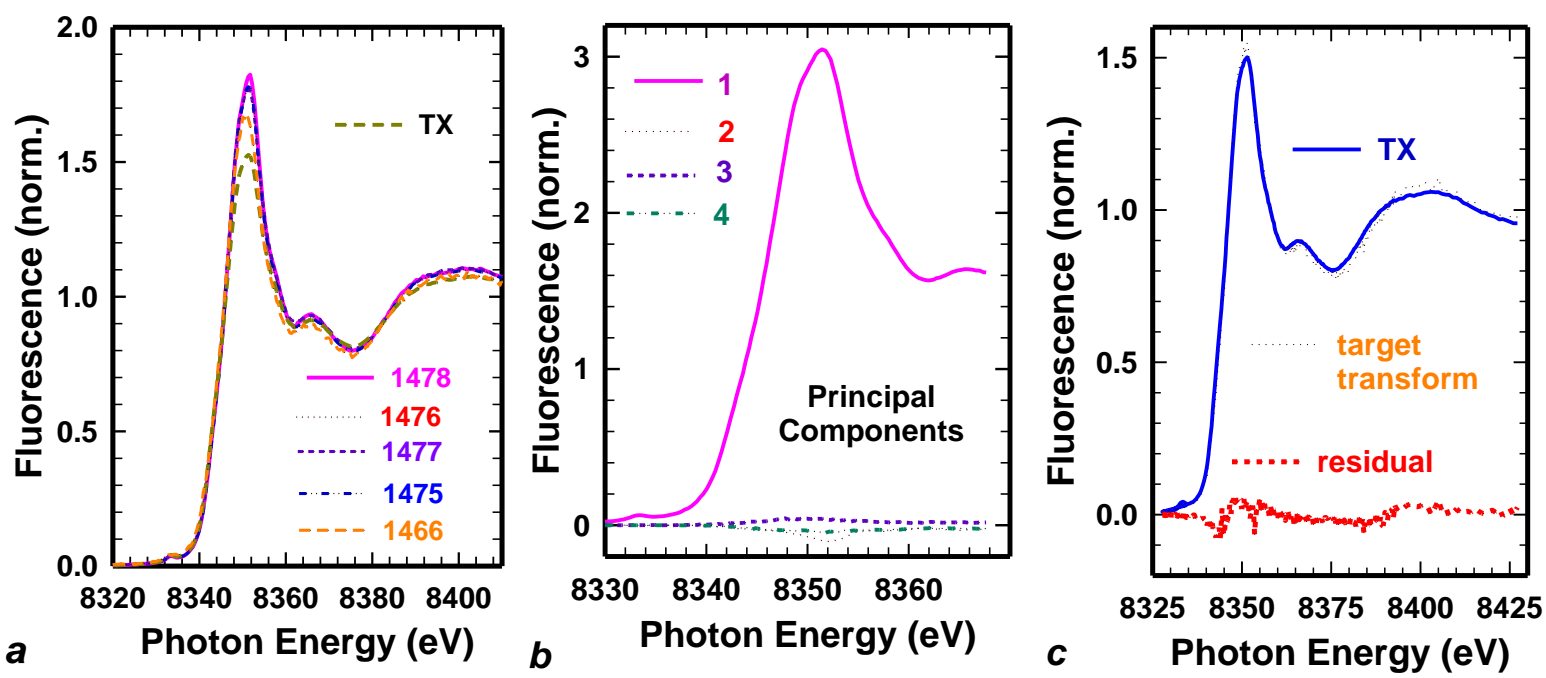

Figure 3. Nickel K edge X-ray absorption near-edge structure spectra of stabilized/solidified products (a) and results of principal component analysis (b) and target transformation (c).

other peaks at higher energy are all in similar locations.

Principal component analysis of the nickel K edge XANES spectra for the five $\mathrm{s} / \mathrm{s}$ products together suggests that $99 \%$ of the variation in Ni speciation between the different $\mathrm{s} / \mathrm{s}$ products can be explained by just one component (Figure 3b). Target transformation (Figure 3c) of the filtercake nickel XANES spectrum suggests that it is a very good fit for the nickel in all 
the s/s products. The evidence from XANES therefore indicates that the nickel speciation does not change from the filtercake to the $\mathrm{s} / \mathrm{s}$ products.

The Fourier transforms of the $\mathrm{k}^{2}$-weighted nickel K edge EXAFS spectra in $\mathrm{r}$ space for the s/s products are shown in Figure 4a, with summary of the corresponding measurements and statistics in Table 6. These spectra may be compared with those for the filtercakes and reference materials, also in Figure 4a. It may be seen that the first peaks (Ni-O) in the pseudo-radial distributions of the s/s products are again at $2.05 \AA$, and the second (Ni-Ni) peaks are again at 3.05 to $3.07 \AA$, similar to the observation for the filtercakes, again also with reduced Ni-Ni peak heights.
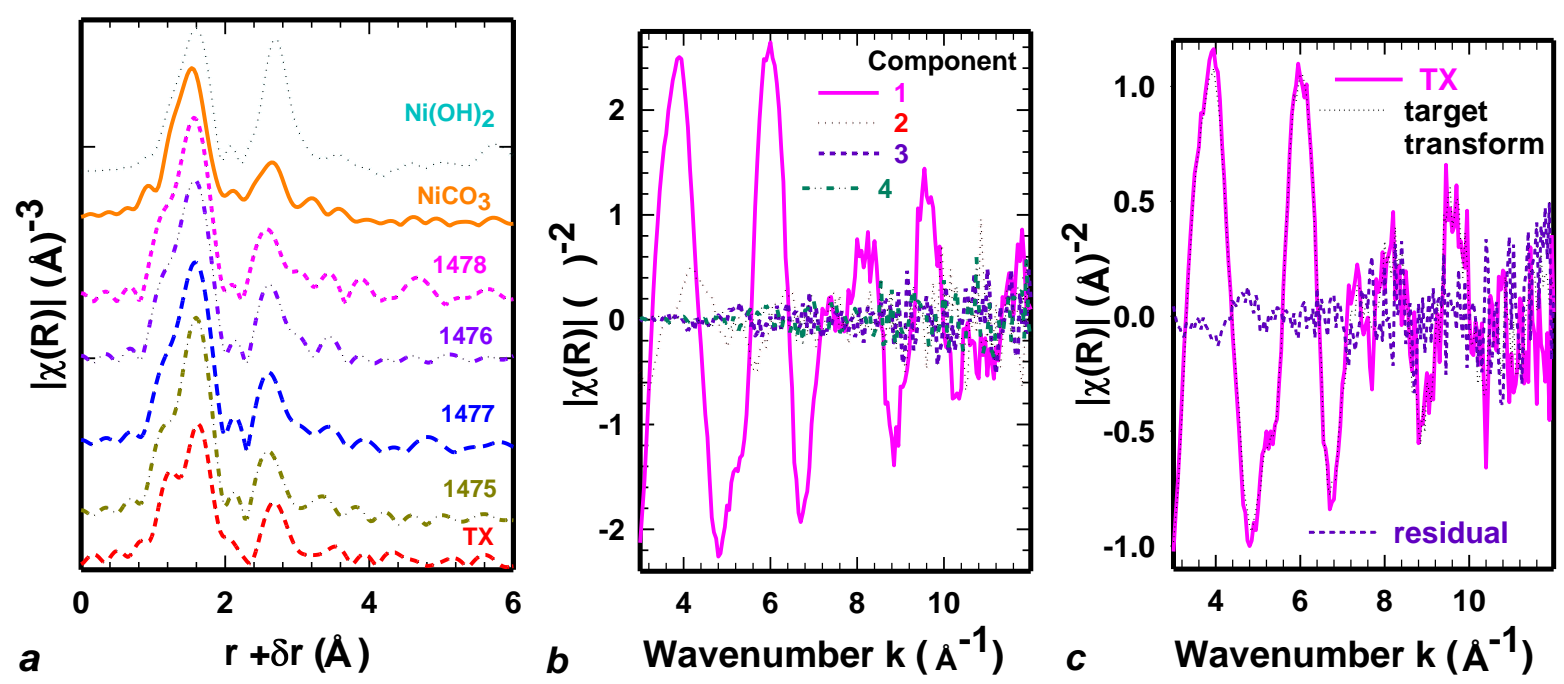

Figure 4. Fourier transforms of the $k^{2}$-weighted nickel $K$ edge extended $X$-ray absorption fine structure spectra of stabilized/solidified products in r space (a), their principal components analysis (b) and target transform of filtercake $T X$.

Principal component analysis of the EXAFS spectra of the s/s products in k space suggests that one component explains $92 \%$ of the variation in nickel speciation (Figure 4c). Target transformation of the filtercake nickel EXAFS spectrum indicates excellent fit to the $\mathrm{s} / \mathrm{s}$ product spectra (Figure 4d). EXAFS thus also suggests that no re-speciation takes place in the chemical environment provided by the $\mathrm{S} / \mathrm{S}$ binders.

XAS therefore clearly shows that there is no respeciation of nickel in the s/s products, which are mechanical mixtures of the filtercake and binders, i.e., nickel is also present in the s/s products as $\alpha$-nickel hydroxide. $\alpha$-nickel hydroxide is a compound of considerable interest due 
to its applications in alkaline storage batteries (e.g., Ni-Cd, Ni-Zn, Ni-Fe, and Ni-MH) and catalysts. Its characteristics, including the layered double hydroxide (LDH) structure of both $\alpha$ and $\beta$-nickel hydroxides is reviewed by Hall et al. [32], whereby Ni can be substituted by other multivalent cations, $\mathrm{Al}, \mathrm{Zn}, \mathrm{Co}$, etc.. $\alpha$-nickel hydroxide is metastable and is supposed to convert to the more stable $\beta$ form over time. Dissolved ions such as Al and $\mathrm{Zn}$ in highly alkaline chemical environments can, however, prevent that phase transformation [36]. In fact, an Alsubstituted form of nickel hydroxide was found in previous research with hydrated cement pastes prepared by mixing solutions of soluble metal salts with cement powder [19]. The presence of $\mathrm{Ni}-\mathrm{LDH}$ should be considered as a possibility, since aluminum is present in the sludge and its solubility increases with $\mathrm{pH}$. XAS, however, cannot distinguish between $\alpha$-nickel hydroxide and Ni-LDH [37].

\section{3 pH-Dependent Leaching}

The concentrations of $\mathrm{Ni}$ leached from both filtercakes and their $\mathrm{s} / \mathrm{s}$ products as a function of $\mathrm{pH}$, in $\mathrm{mg} / \mathrm{kg}$ of filtercake are shown relative to their total concentrations in Figure 5a. The similarity of nickel speciation in the filtercakes and $\mathrm{s} / \mathrm{s}$ products is reflected in the trend for nickel leaching as a function of $\mathrm{pH}$, where leached concentrations from both the filtercakes and $\mathrm{s} / \mathrm{s}$ products lie along the same curve. Nickel is essentially completely available for leaching below $\mathrm{pH} \sim 5$, but is 3-4 orders of magnitude lower at $\mathrm{pH} 8-12$. This suggests that any change in nickel solubility is a function of $\mathrm{pH}$ alone, though the leaching results cannot confirm whether only one species is present in the solid at $\mathrm{pH}$ values above 6 , and leaching of nickel from $\mathrm{s} / \mathrm{s}$ products may also be affected by physical encapsulation.

$\mathrm{pH}$ dependent leaching of $\mathrm{Cr}, \mathrm{Cu}$ and $\mathrm{Zn}$ from these samples has also been shown in Figure $5 \mathrm{~b}, \mathrm{c}$ and $\mathrm{d}$, as a matter of general interest for these matrices. The most alkaline condition represents the $\mathrm{pHs}$ without acid addition, which ranged from 8.2-9.4 for the filtercakes, and from 11.7 to 12.3 for the s/s products. It may be observed that leaching of $\mathrm{Cr}$ is highly variable and was decreased for s/s products containing ggbs. Examination of Cr speciation by XAS [22] suggests that only a tiny fraction of $\mathrm{Cr}$ is present as leachable $\mathrm{Cr}(\mathrm{VI})$, but this seems to be variable and determines leachate concentrations for the non-ggbs matrices. The small proportion of $\mathrm{Cr}(\mathrm{V})$ may be reduced to $\mathrm{Cr}(\mathrm{III})$ by ggbs addition, decreasing leachability at neutral $\mathrm{pH}$. $\mathrm{Cu}$ is likely associated with dissolved organic carbon in the leachates [38], and its availability at low 
$\mathrm{pH}$ is also decreased by ggbs addition, perhaps by formation of $\mathrm{CuS}$. Zn demonstrates $\mathrm{pH}$ dependent leachability in the s/s products, as in the filtercakes, and is not fully available even at low $\mathrm{pH}$, neither in the filtercakes nor the $\mathrm{s} / \mathrm{s}$ products.

\section{Conclusions}

This work applied a portfolio of techniques to examination of the mineralogy of real metal treatment filtercakes with a bulk chemical composition dominated by calcium hydroxide and/or carbonate, and the effect of S/S on Ni speciation. Peaks of $\alpha$-nickel hydroxide identified in the metal treatment filtercakes were near the detection limit by XRD and could not be seen after $\mathrm{S} / \mathrm{S}$. The use of nickel $\mathrm{K}$ edge XAS as a more sensitive technique to examine element speciation at relatively low concentrations in complex matrices was demonstrated, and showed that nickel is indeed present in the $\alpha$-nickel hydroxide form in the filtercakes, and that $\mathrm{S} / \mathrm{S}$ with five different binder systems did not induce its respeciation. Leaching in the acid neutralization capacity test is consistent with physical encapsulation of the waste in the binder.

Respeciation of the high concentrations of chromium, copper and zinc present in metal treatment filtercakes by treatment with $\mathrm{S} / \mathrm{S}$ is a potential subject for future work.

\section{Acknowledgements}

The authors wish to acknowledge that samples for this work were provided by the ProCeSS project, which was funded through the UK Technology Strategy Board. We are grateful for the competent preparation of these samples by Dr Judith Zhou and Dr Aiduan Li Borrion at UCL. 


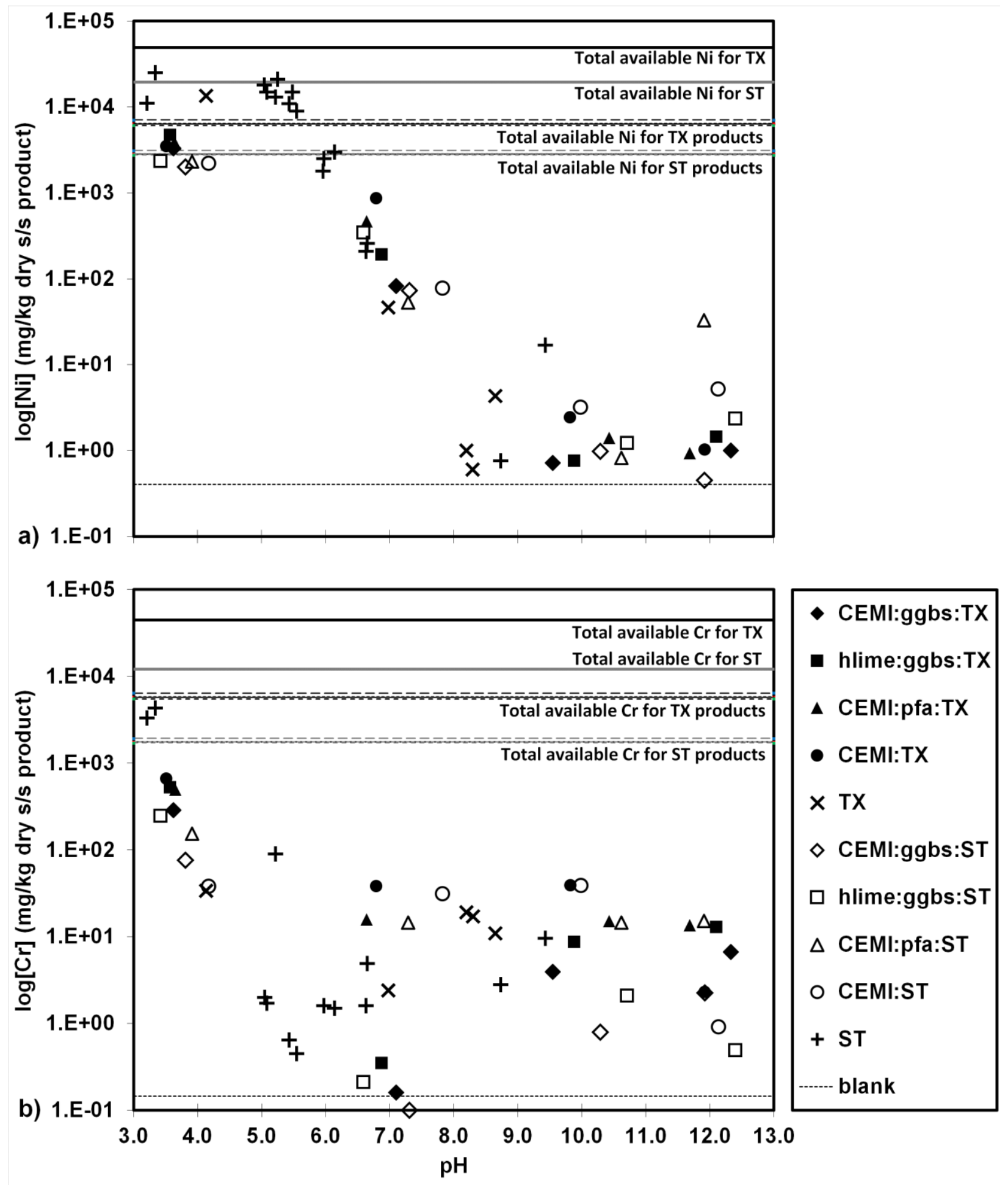




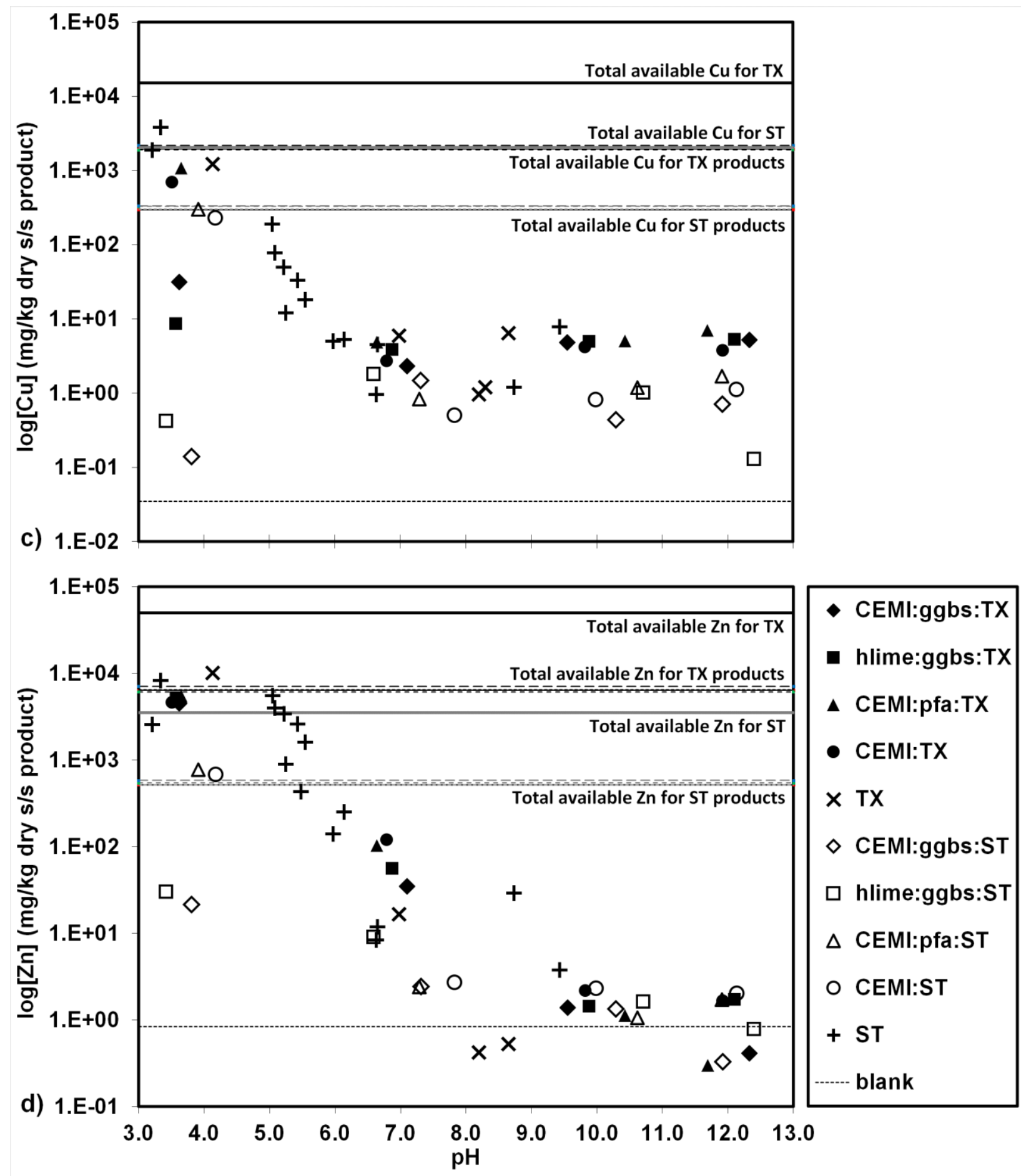

Figure 5. pH-dependent leaching of nickel (a), chromium (b), copper (c) and zinc (d) from filtercakes and stabilized/solidified products. 


\section{References}

[1] C. Jantzen, A. Johnson, D. Read, J.A. Stegemann, Cements in waste management, Advances in Cement Research, 22 (2010) 225-231.

[2] C.Y. Yin, W.S.W. Ali, Y.P. Lim, Oil palm ash as partial replacement of cement for solidification/stabilization of nickel hydroxide sludge, Journal of Hazardous Materials, 150 (2008) 413-418.

[3] C. Belebchouche, K. Moussaceb, A. Ait-Mokhtar, Evaluation of the encapsulation of nickel, chromium and lead-rich wastes in cement matrices by TCLP test, European Journal of Environmental and Civil Engineering, 20 (2016) 711-724.

[4] E.E. Hekal, W.S. Hegazi, E.A. Kishar, M.R. Mohamed, Solidification/stabilization of Ni(II) by various cement pastes, Construction and Building Materials, 25 (2011) 109-114.

[5] R. Cioffi, M. Lavorgna, L. Santoro, Environmental and technological effectiveness of a process for the stabilization of a galvanic sludge, Journal of Hazardous Materials, 89 (2002) 165 175.

[6] M. Saeedi, A.R. Bazkiaei, Z. Torkaman, Insights in Leaching Characteristis Assessment of Solidified Wastes Using Different Leach tests, International Journal of Environmental Research, 4 (2010) 455-462.

[7] A. Tessier, P.G.C. Campbell, M. Bisson, SEQUENTIAL EXTRACTION PROCEDURE FOR THE SPECIATION OF PARTICULATE TRACE-METALS, Analytical Chemistry, 51 (1979) 844-851.

[8] J.A. Stegemann, P.L. Cote, SUMMARY OF AN INVESTIGATION OF TEST METHODS FOR SOLIDIFIED WASTE EVALUATION, Waste Management, 10 (1990) 41-52.

[9] T.L. Rinehart, D.G. Schulze, R.M. Bricka, S. Bajt, E.R. Blatchley, Chromium leaching vs. oxidation state for a contaminated solidified/stabilized soil, Journal of Hazardous Materials, 52 (1997) 213-221.

[10] M. Vespa, R. Daehn, D. Grolimund, E. Wieland, A.M. Scheidegger, Co speciation in hardened cement paste: A macro- and micro-spectroscopic investigation, Environmental Science \& Technology, 41 (2007) 1902-1908.

[11] M.C. Hsiao, H.P. Wang, Y.W. Yang, EXAFS and XANES studies of copper in a solidified fly ash, Environmental Science \& Technology, 35 (2001) 2532-2535.

[12] J. Rose, I. Moulin, J.L. Hazemann, A. Masion, P.M. Bertsch, J.Y. Bottero, F. Mosnier, C. Haehnel, X-ray absorption spectroscopy study of immobilization processes for heavy metals in calcium silicate hydrates: 1. Case of lead, Langmuir, 16 (2000) 9900-9906.

[13] P. Mandaliev, R. Daehn, B. Wehrli, E. Wielandt, Macro- and Microspectroscopic Study of Nd (III) Uptake Mechanisms in Hardened Cement Paste, Environmental Science \& Technology, 43 (2009) 8462-8468.

[14] I. Bonhoure, I. Baur, E. Wieland, C.A. Johnson, A.M. Scheidegger, Uptake of Se(IV/VI) oxyanions by hardened cement paste and cement minerals: An X-ray absorption spectroscopy study, Cement and Concrete Research, 36 (2006) 91-98.

[15] I. Bonhoure, E. Wieland, A.M. Scheidegger, M. Ochs, D. Kunz, EXAFS study of Sn(IV) immobilization by hardened cement paste and calcium silicate hydrates, Environmental Science \& Technology, 37 (2003) 2184-2191.

[16] E. Wieland, N. Mace, R. Daehn, D. Kunz, J. Tits, Macro- and micro-scale studies on U(VI) immobilization in hardened cement paste, Journal of Radioanalytical and Nuclear Chemistry, 286 (2010) 793-800. 
[17] J. Rose, I. Moulin, A. Masion, P.M. Bertsch, M.R. Wiesner, J.Y. Bottero, F. Mosnier, C. Haehnel, X-ray absorption spectroscopy study of immobilization processes for heavy metals in calcium silicate hydrates. 2. Zinc, Langmuir, 17 (2001) 3658-3665.

[18] M. Vespa, R. Daehn, E. Gallucci, D. Grolimund, E. Wieland, A.M. Scheidegger, Microscale investigations of ni uptake by cement using a combination of scanning electron microscopy and synchrotron-based techniques, Environmental Science \& Technology, 40 (2006) 7702-7709.

[19] M. Vespa, R. Dahn, D. Grolimund, E. Wieland, A.M. Scheidegger, Spectroscopic investigation of Ni speciation in hardened cement paste, Environmental Science \& Technology, 40 (2006) 2275-2282.

[20] M. Vespa, R. Daehn, E. Wieland, D. Grolimund, A.M. Scheidegger, THE INFLUENCE OF HYDRATION TIME ON THE Ni UPTAKE BY CEMENT, Czechoslovak Journal of Physics, 56 (2006) D599-D607.

[21] A. Roy, H.C. Eaton, F.K. Cartledge, M.E. Tittlebaum, SOLIDIFICATION

STABILIZATION OF HAZARDOUS-WASTE - EVIDENCE OF PHYSICAL

ENCAPSULATION, Environmental Science \& Technology, 26 (1992) 1349-1353.

[22] A. Roy, Merchan, G., Zhou, Q., Stegemann, J. A., Speciation of Chromium in Solidified/

Stabilized Waste Form, in: XAS 14, Camerino Italy, 2009.

[23] J.A. Stegemann, Q. Zhou, Development of process envelopes for cement-based

stabilisation/solidification of metal treatment filtercakes, in: M. Zamorano, C.A. Brebbia, A.

Kungolos, V. Popov, H. Itoh (Eds.) Waste Management and the Environment Iv, 2008, pp. 2130.

[24] J.A. Stegemann, Process Envelopes for Cement-based Stabilisation/ Solidification - Final

Technical Summary Report. London, UK: , in, University College London, University College London, UK, 2010.

[25] B. Ravel, M. Newville, ATHENA, ARTEMIS, HEPHAESTUS: data analysis for X-ray absorption spectroscopy using IFEFFIT, J. Synchrot. Radiat., 12 (2005) 537-541.

[26] T. Ressler, WinXAS: a program for X-ray absorption spectroscopy data analysis under MSWindows, J. Synchrot. Radiat., 5 (1998) 118-122.

[27] T.N. Ramesh, P.V. Kamath, Planar defects in layered hydroxides: Simulation and structure refinement of beta-nickel hydroxide, Materials Research Bulletin, 43 (2008) 3227-3233.

[28] J.A. Stegemann, P.L. Cote, Investigation of Test Methods for Solidified Waste Evaluation A Cooperative Program, in: Manuscript Series TS-15, Environment Canada Wastewater Technology Centre, Burlington, Ontario, Canada., 1991.

[29] P. Genin, A. Delahayevidal, F. Portemer, K. Tekaiaelhsissen, M. Figlarz, PREPARATION AND CHARACTERIZATION OF ALPHA-TYPE NICKEL HYDROXIDES OBTAINED BY CHEMICAL PRECIPITATION - STUDY OF THE ANIONIC SPECIES, European Journal of Solid State and Inorganic Chemistry, 28 (1991) 505-518.

[30] I. Richardson, H.F.W. Taylor, Cement Chemistry, ICE Publishing, 2015.

[31] K. Sisomphon, L. Franke, Evaluation of calcium hydroxide contents in pozzolanic cement pastes by a chemical extraction method, Construction and Building Materials, 25 (2011) 190194.

[32] D.S. Hall, D.J. Lockwood, C. Bock, B.R. MacDougall, Nickel hydroxides and related materials: a review of their structures, synthesis and properties, Proceedings. Mathematical, Physical, and Engineering Sciences / The Royal Society, 471 (2015) 20140792. 
[33] K.I. Pandya, W.E. O'Grady, D.A. Corrigan, J. McBreen, R.W. Hoffman, Extended x-ray absorption fine structure investigations of nickel hydroxides, The Journal of Physical Chemistry, 94 (1990) 21-26.

[34] H. Kurama, Treatment and Recovery of Nickel Rich Precipitate from Plating Plant Waste, Journal of Environmental Engineering and Landscape Management, 17 (2009) 212-218. [35] L. Fernández-Carrasco, D. orrens-Martín, L.M. Morales, S. Martínez-Ramírez, Infrared Spectroscopy in the Analysis of Building and Construction Materials, Infrared Spectroscopy Materials Science, Engineering and Technology, in: T. Theophile (Ed.) Infrared Spectroscopy in the Analysis of Building and Construction Materials, Infrared Spectroscopy - Materials Science, Engineering and Technology, 2012, pp. 369-382.

[36] R.S. Jayashree, P.V. Kamath, Suppression of the alpha -> beta-nickel hydroxide transformation in concentrated alkali: Role of dissolved cations, Journal of Applied Electrochemistry, 31 (2001) 1315-1320.

[37] A.C. Scheinost, R.G. Ford, D.L. Sparks, The role of Al in the formation of secondary Ni precipitates on pyrophyllite, gibbsite, talc, and amorphous silica: a DRS study, Geochim. Cosmochim. Acta, 63 (1999) 3193-3203.

[38] M. McBride, S. Sauve, W. Hendershot, Solubility control of $\mathrm{Cu}, \mathrm{Zn}, \mathrm{Cd}$ and $\mathrm{Pb}$ in contaminated soils, Eur J Soil Sci 48(1997) 337-346. 


\section{$\underline{\text { Figure Captions }}$}

Figure 1. a) X-ray diffraction patterns for filtercakes TX and ST (inset); (b) Fourier transform infrared spectroscopy patterns for filtercakes TX and ST, compared with calcite; (c) Thermogravimetric patterns for filtercakes TX and ST, compared with calcite; and (d) X-ray absorption near edge spectroscopy patterns for filtercakes TX and ST, compared with $\beta$-nickel hydroxide and nickel carbonate.

Figure 2. X-ray diffraction patterns (a), Fourier transform infrared patterns (b), and differential thermogravimetric curves (c) of stabilized/solidified products (see Table 2 for formulations).

Figure 3. Nickel K edge X-ray absorption near-edge structure spectra of stabilized/solidified products (a) and results of principal component analysis (b) and target transformation (c).

Figure 4. Fourier transforms of the $\mathrm{k}^{2}$-weighted nickel $\mathrm{K}$ edge extended $\mathrm{X}$-ray absorption fine structure spectra of stabilized/solidified products in $r$ space (a), their principal components analysis (b) and target transform of filtercake TX.

Figure 5. pH-dependent leaching of nickel in filtercakes and stabilized/solidified products. 
$\underline{\text { Tables }}$

Table 1. Compositions of metal treatment filtercakes

\begin{tabular}{|c|c|c|c|c|c|c|c|c|}
\hline \multicolumn{2}{|c|}{ Filtercake } & & \multicolumn{4}{|c|}{ TX } \\
\hline & Average & CoV & Range & (n) & Average & CoV & Range & (n) \\
\hline \multicolumn{9}{|c|}{ Metals in $\mathrm{mg} / \mathrm{kg}$ dry mass } \\
\hline $\mathrm{Al}$ & 9000 & $35 \%$ & $2,700-14,000$ & (9) & 38,000 & $28 \%$ & $2,7000-5,5000$ & (7) \\
\hline $\mathrm{Ba}$ & 140 & $32 \%$ & $71-200$ & (9) & 400 & $13 \%$ & $320-440$ & $(5)$ \\
\hline $\mathrm{Ca}$ & 220,000 & $49 \%$ & $57,000-370,000$ & $(10)$ & 110,000 & $96 \%$ & $32,000-250,000$ & (5) \\
\hline $\mathrm{Cd}$ & 250 & $52 \%$ & $59-430$ & (9) & 170 & $68 \%$ & $42-320$ & (7) \\
\hline $\mathrm{Co}$ & 7 & $24 \%$ & $5.4-10$ & (6) & 960 & $73 \%$ & $10-1,700$ & $(5)$ \\
\hline $\mathrm{Cr}$ & 13,000 & $35 \%$ & $3,500-17,000$ & (9) & 44,000 & $44 \%$ & $4,700-69,000$ & (6) \\
\hline $\mathrm{Cu}$ & 2,300 & $50 \%$ & $600-4,100$ & (8) & 16,000 & $35 \%$ & $8,900-22,000$ & (7) \\
\hline $\mathrm{Fe}$ & 8,400 & $60 \%$ & $2,400-21,700$ & $(10)$ & 38,000 & $32 \%$ & $22,000-57,000$ & (7) \\
\hline $\mathrm{K}$ & 220 & $204 \%$ & $8-1,200$ & (7) & 520 & $103 \%$ & $38-1,200$ & $(5)$ \\
\hline $\mathrm{Mg}$ & 7,200 & $32 \%$ & $2,300-9,000$ & (7) & 10,000 & $82 \%$ & $800-17,000$ & $(5)$ \\
\hline $\mathrm{Mn}$ & 390 & $37 \%$ & $250-640$ & (9) & 1,600 & $21 \%$ & $1,100-2,100$ & (7) \\
\hline $\mathrm{Na}$ & 2,900 & $133 \%$ & $31-11,000$ & (9) & 2,000 & $198 \%$ & $55-9,000$ & (5) \\
\hline $\mathrm{Ni}$ & 19,000 & $33 \%$ & $7,600-27,000$ & (9) & 48,000 & $17 \%$ & $38,000-64,000$ & (7) \\
\hline $\mathrm{P}$ & 5,100 & $55 \%$ & $480-7,500$ & (8) & 25,000 & $90 \%$ & $150-45,000$ & $(5)$ \\
\hline $\mathrm{Pb}$ & 350 & $45 \%$ & $130-610$ & (8) & 800 & $61 \%$ & $330-1,400$ & (7) \\
\hline $\mathrm{Sb}$ & $<10$ & NA & $<10$ & (3) & 160 & $153 \%$ & $3.4-580$ & (3) \\
\hline $\mathrm{Si}$ & 7,600 & $81 \%$ & $3,500-21,000$ & (7) & 18,000 & $161 \%$ & $710-70,000$ & (5) \\
\hline $\mathrm{Sn}$ & 430 & $37 \%$ & $230-650$ & (7) & 4,000 & $63 \%$ & $530-7,700$ & (5) \\
\hline $\mathrm{Sr}$ & 710 & $52 \%$ & $75-1,100$ & (9) & 172 & $91 \%$ & $25-440$ & (5) \\
\hline $\mathrm{Zn}$ & 4,100 & $41 \%$ & $1,700-6,400$ & $(9)$ & 63,000 & $7 \%$ & $58,000-69,000$ & $(6)$ \\
\hline \multicolumn{9}{|c|}{$\underline{\text { Anions in } \mathrm{mg} / \mathrm{kg} \text { dry mass* }}$} \\
\hline $\mathrm{Cl}^{-}$ & 840 & $77 \%$ & $380-1,300$ & (2) & 3900 & $44 \%$ & $2,700-5,100$ & (2) \\
\hline $\mathrm{NO}_{3}^{-}$ & 100 & $135 \%$ & $4.7-200$ & (2) & 9.0 & NA & 9.0 & (1) \\
\hline $\mathrm{SO}_{4}^{2-}$ & 1600 & $32 \%$ & $1,200-1,900$ & $(2)$ & 4100 & $10 \%$ & $3,800-4,400$ & $(2)$ \\
\hline $\mathrm{pH}^{*}$ & 8.9 & $4 \%$ & $8.6-9.4$ & (4) & 8.4 & $3 \%$ & $8.2-8.7$ & (3) \\
\hline LOI & $45 \%$ & $32 \%$ & $26-61$ & $(5)$ & $31 \%$ & NA & $31 \%$ & (1) \\
\hline TOC & $4.5 \%$ & $107 \%$ & $0.41-9.9$ & (3) & $1.2 \%$ & $43 \%$ & $0.6-1.6 \%$ & $(2)$ \\
\hline
\end{tabular}

$\mathrm{CoV}=$ Coefficient of Variation $=100 \mathrm{x}$ Standard Deviation/Average; $\mathrm{n}=$ number of samples; LOI $=$ loss on ignition at $550^{\circ} \mathrm{C} ; \mathrm{TOC}=$ total organic carbon; $\mathrm{NA}=$ not applicable

*based on distilled water extraction at liquid:solid ratio of 10:1 
Table 2. Stabilized/solidified product formulations (\% total dry mass)[23]

\begin{tabular}{l|c|c|c|c|c|c}
\hline Sample & CEMI & hlime & ggbs & pfa & $\begin{array}{c}\text { Filtercake } \\
\text { TX }\end{array}$ & Water \\
\hline 1475 (CEMI:ggbs:TX) & 7.5 & & 67.5 & & 25.0 & 46.5 \\
1476 (hlime:ggbs:TX) & & 15.0 & 60.0 & & 25.0 & 46.5 \\
1477 (CEMI:pfa:TX) & 16.4 & & & 58.6 & 25.0 & 46.5 \\
1466 & 18.3 & & & 72.5 & 9.2 & 44.9 \\
1478 (CEMI:TX) & 75.0 & & & & 25.0 & 46.5 \\
\hline
\end{tabular}

$\overline{\mathrm{CEMI}}=$ Portland cement; hlime $=$ hydrated lime; $\mathrm{pfa}=$ pulverized fuel ash $=$ power plant fly ash; ggbs $=$ ground granulated blast furnace slag 
Table 3. Concentrations of selected elements in stabilized/solidified products $(\mathrm{mg} / \mathrm{kg}$ dried mass)

\begin{tabular}{|c|c|c|c|c|c|}
\hline & $\begin{array}{c}1475 \\
\text { CEMI:ggbs:TX }\end{array}$ & $\begin{array}{c}1476 \\
\text { hlime:ggbs:TX }\end{array}$ & $\begin{array}{c}1477 \\
\text { CEMI:pfa:TX }\end{array}$ & 1466 & $\begin{array}{c}1478 \\
\text { CEMI:TX }\end{array}$ \\
\hline $\mathbf{F e}$ & 4600 & 3000 & 17700 & 19600 & 10400 \\
\hline $\mathrm{Cr}$ & 6800 & 6900 & 6500 & 2500 & 7600 \\
\hline $\mathrm{Cu}$ & 1200 & 1200 & 1200 & 480 & 1400 \\
\hline $\mathbf{N i}$ & 6300 & 6400 & 6000 & 2300 & 7000 \\
\hline $\mathbf{Z n}$ & 7500 & 7500 & 7100 & 2700 & 8300 \\
\hline
\end{tabular}


Table 4. Reference materials used for comparison with filtercakes and stabilized/solidified products

\begin{tabular}{lll}
\hline Mineral Phase & Chemical & Source \\
\hline aragonite & $\mathrm{CaCO}_{3}$ & Natural coral \\
calcite & $\mathrm{CaCO}_{3}$ & Sigma Aldrich (>99\%; CAS\# 471-34-1) \\
metal & $\mathrm{Ni}$ foil & EXAFS Company \\
bunsenite & $\mathrm{NiO}$ & Alfa Aesar (>99.99\%; CAS\# 1313-99-1) \\
$\beta$-nickel hydroxide & $\mathrm{Ni}(\mathrm{OH})_{2}$ & Alfa Aesar (CAS \#12054-48-7) \\
& $\mathrm{NiCO}_{3}$ & ACROS (CAS\# 3333-67-3) \\
\hline
\end{tabular}


Table 5. Quantification* of calcium hydroxide and calcium carbonate in filtercakes and stabilized/solidified products from thermogravimetry

\begin{tabular}{lrrrrrrr}
\hline$\%$ & ST & TX & $\mathbf{1 4 7 5}$ & $\mathbf{1 4 7 6}$ & $\mathbf{1 4 7 7}$ & $\mathbf{1 4 6 6}$ & $\mathbf{1 4 7 8}$ \\
\hline $\mathbf{C a}(\mathbf{O H})_{2}$ & 19 & $\mathrm{ND}$ & 14 & 2.3 & 2.3 & 4.2 & $\mathrm{ND}$ \\
$\mathbf{C a C O}_{3}$ & 8.8 & 73 & 16 & 18 & 14 & 10 & 36 \\
* based on $74 \mathrm{~g} \mathrm{Ca}(\mathrm{OH})_{2} / \mathrm{g}$ mass lost as $\mathrm{H}_{2} \mathrm{O} ; 100 \mathrm{~g} \mathrm{CaCO}_{3} / \mathrm{g}$ mass lost as $\mathrm{CO}_{2}$ \\
$\mathrm{ND}=$ not detected
\end{tabular}


Table 6. Fitting of extended X-ray absorption fine structure spectra for stabilized/solidified products.

\begin{tabular}{|c|c|c|c|c|c|c|c|}
\hline Sample & Shell & $\mathbf{N a}$ & $\mathbf{R}^{\mathbf{b}}(\AA)$ & $\sigma^{2}\left(\times 10^{-3}\right)$ & E0 & $\mathbf{S}_{0}{ }^{2}$ & $\mathbf{R}(\%)$ \\
\hline \multirow{2}{*}{ bunsenite } & $\mathrm{Ni}-\mathrm{O}$ & $6 *$ & 2.07 & $0.5^{*}$ & $0.32 \pm 1.47$ & 0.80 & 6.58 \\
\hline & $\mathrm{Ni}-\mathrm{Ni}$ & $12 *$ & 2.93 & $0.6^{*}$ & $-3.93 \pm 0.45$ & & \\
\hline \multirow{3}{*}{$\begin{array}{l}\beta \text {-nickel } \\
\text { hydroxide }\end{array}$} & $\mathrm{Ni}-\mathrm{O}$ & 5.51 & 2.05 & $0.6^{*}$ & $-3.27 \pm 0.07$ & & 6.73 \\
\hline & & & & & & & \\
\hline & $\mathrm{Ni}-\mathrm{Ni}$ & 5.63 & 3.12 & $0.6^{*}$ & $-0.71 \pm 0.05$ & & \\
\hline \multirow[t]{2}{*}{ ST } & $\mathrm{Ni}-\mathrm{O}$ & $6^{*}$ & 2.04 & 0.53 & $-3.27 *$ & & 6.66 \\
\hline & $\mathrm{Ni}-\mathrm{Ni}$ & 3.89 & 3.05 & 0.69 & $-3.58 \pm 0.07$ & & \\
\hline \multirow[t]{2}{*}{$\mathbf{T X}$} & $\mathrm{Ni}-\mathrm{O}$ & $6^{*}$ & 2.04 & 0.69 & $-1.50 \pm 0.07$ & $0.8^{*}$ & 7.61 \\
\hline & $\mathrm{Ni} \mathrm{Ni}$ & 3.49 & 3.06 & 0.85 & $-2.85 \pm 0.13$ & & \\
\hline \multirow[t]{2}{*}{1475} & $\mathrm{Ni}-\mathrm{O}$ & $6^{*}$ & 2.06 & 0.6 & $-1.84 \pm 0.93$ & $0.8^{*}$ & 7.60 \\
\hline & $\mathrm{Ni}-\mathrm{Ni}$ & 3.39 & 3.06 & 0.8 & $-5.97 \pm 0.19$ & & \\
\hline \multirow[t]{2}{*}{1476} & $\mathrm{Ni}-\mathrm{O}$ & $6^{*}$ & 2.05 & 0.45 & $-3.27^{*}$ & & 5.86 \\
\hline & $\mathrm{Ni}-\mathrm{Ni}$ & 2.57 & 3.07 & 0.39 & $-3.64 \pm 0.07$ & & \\
\hline \multirow[t]{2}{*}{1477} & $\mathrm{Ni}-\mathrm{O}$ & $6^{*}$ & 2.05 & 0.4 & $-1.80 \pm 0.05$ & & 6.56 \\
\hline & $\mathrm{Ni}-\mathrm{Ni}$ & 2.96 & 3.06 & 0.5 & $-3.48 \pm 0.08$ & & \\
\hline \multirow[t]{2}{*}{1478} & $\mathrm{Ni}-\mathrm{O}$ & $6 *$ & 2.05 & 0.45 & $-0.94 \pm 0.077$ & & 6.74 \\
\hline & $\mathrm{Ni}-\mathrm{Ni}$ & 4.64 & 3.07 & 0.90 & $-3.09 \pm 0.131$ & & \\
\hline
\end{tabular}

$\mathrm{N}$ - coordination number; $\mathrm{R}$ - interatomic distance; $\sigma^{2}$ - Debye Waller factor; $\mathrm{E}_{0}$ - Binding energy; $\mathrm{S}_{0}^{2}-$ amplitude reduction factor; Reduced $\chi 2 ; \mathrm{a}-20 \%$; Fit quality estimated accuracy a $20 \%, \mathrm{~b}- \pm 0.02 \AA ;$ *held constant. 